This is the author's final, peer-reviewed manuscript as accepted for publication. The publisher-formatted version may be available through the publisher's web site or your institution's library.

\title{
Examining the impact of consumer feedback on internet product evaluation: comparing base-rate and case history information
}

Stephen C. Nettelhorst, Laura A. Brannon, W. Trey Hill

How to cite this manuscript

If you make reference to this version of the manuscript, use the following information:

Nettelhorst, S. C., Brannon, L. A., \& Hill, W. T. (2013). Examining the impact of consumer feedback on internet product evaluation: Comparing base-rate and case history information. Retrieved from http://krex.ksu.edu

\section{Published Version Information}

Citation: Nettelhorst, S. C., Brannon, L. A., \& Hill, W. T. (2013). Examining the impact of consumer feedback on internet product evaluation: Comparing base-rate and case history information. Computers in Human Behavior, 29(4), 1290-1294.

Copyright: () 2013 Elsevier Ltd.

Digital Object Identifier (DOI): doi:10.1016/j.chb.2013.01.035

Publisher's Link: http://www.sciencedirect.com/science/article/pii/S0747563213000381

This item was retrieved from the K-State Research Exchange (K-REx), the institutional repository of Kansas State University. K-REx is available at http://krex.ksu.edu 
Examining the impact of consumer feedback on internet product evaluation: Comparing baserate and case history information 


\begin{abstract}
Two important pieces of information for consumers evaluating products online are consumer ratings (i.e. base-rates) and consumer reviews (i.e. case histories). While literature in cognitive psychology shows a tendency to weigh case history information more heavily than base-rate information, other consumer oriented studies show the opposite. This study examined the relative impact of each type of information by treating consumer ratings and reviews as orthogonal factors and then manipulating the valence of each type of information. Participants evaluated a novel health beverage by viewing consumer ratings and/or reading their reviews about the product. Results indicated that the valence of the base-rate information significantly affected participants' evaluation of the product only when case history information was not presented. When case history information was presented, the valence of such information significantly affected participants' evaluation of the product regardless of the valence of any base-rate information. These results demonstrate that base-rate neglect may bias individuals' evaluations of products since base-rate information tends to be more representative of a population than case history information. Thus determining ways of making base-rate information more impactful in consumer settings is an important goal.
\end{abstract}

Keywords: persuasive computing; e-commerce; social cognition. 


\section{Introduction}

Consumers typically rely on two types of information when evaluating products online. The first, known as base-rate information, is a quantitative rating of a product. The second, known as case history information, is a qualitative review of the product given by a few consumers who are motivated to write such reviews. The importance of both types of information is easily discernible by the fact that they are placed in the most important areas of a product's webpage. While both types of information are important for potential consumers, research examining the relative importance of each type of information is mixed.

Several studies (mostly from judgment and decision making literatures) suggest that individuals rely on case history information more than base-rate information when evaluating or making future predictions about a certain item (Borgida \& Nisbett, 1977; Dickson, 1982;

Ginosar \& Trope, 1980; Hamill, Wilson, \& Nisbett, 1980; Kahneman \& Tversky, 1973; Koballa, 1986; Nisbett \& Borgida, 1975). Base-rate information has an effect, but its impact is secondary to case history information (Ginosar \& Trope, 1980; Kahneman \& Tversky, 1973). In contrast, several studies using more consumer oriented contexts suggest that base-rate information has a larger effect than case history information (Allen \& Preiss, 1997; Baseler \& Burgoon, 1994; Krupat, Smith, Leach, \& Jackson, 1997). Finally, some research suggests that base-rate and case history have equivalent effects on individuals' evaluations (Kazoleas, 1993), or that the impact of each type of information is moderated by factors such as temporal distance (Ledgerwood, Wakslak, \& Wang, 2010) or value-congruency (Slater \& Rouner, 1996).

Base-rate neglect in judgment and decision making (JDM) is regarded as a fallacy and was part of the "heuristics and biases" program (Kahneman \& Tversky, 1972; 1973). Although much of the research on base-rate neglect is within the paradigm of structured Bayesian 
reasoning, the supposed neglect of base-rate information is relevant to many other areas of research which may implicitly assume a type of simple Bayesian updating. For example, when forming an opinion of a product, we are essentially estimating the posterior probability that it is a good (or bad) product.

Kahneman and Tversky (1973) examined representativeness in the "Tom W. problem" by having three groups of participants provide three different types of estimates. A base-rate group provided estimates of the proportions of graduate students currently enrolled in nine different areas of specialization (e.g., Business Administration, Engineering) in the United States. This provided a baseline estimate of base-rate, signifying the proportions of students believed to be enrolled in each discipline at that time. The data showed that participants believed the largest proportion of graduate students to be enrolled in the Humanities and Education (20\%). A second group, the similarity group was given a personality sketch of Tom W. which illustrated qualities stereotypical of an engineer or computer scientist. Participants in this group were asked to rate Tom W.'s similarity to the typical graduate student in each of the nine areas. Participants in the similarity group ranked Tom W.'s personality sketch as most similar to computer science and engineering majors, and least similar to social science and humanities and education majors. The third group of participants, the prediction group, were given the personality sketch and told that it was provided by Tom W.'s high school guidance counselor during his senior year. Participants were then asked to rank the nine areas of specialization based on how likely Tom W. is now a graduate student in each discipline. Results of the prediction group provided the critical evaluation that participants' rankings of likelihood were positively correlated with similarity (group two), but negatively correlated with base-rate estimates (group one). These data suggested that, when making estimates of the likelihood of a categorization, people tend to focus on the 
similarity (or representativeness) between an outcome option and a piece of evidence (the personality sketch), while neglecting internal conceptions about the base-rates and prior probabilities of different outcome options.

A later study in the same paper demonstrated that, even when representative information and base-rates were simultaneously presented, people tended to make intuitive judgments based more heavily on representative information while underweighting the base-rate. In the lawyer/engineer problem, participants were told that psychologists had administered personality tests to 30 engineers and 70 lawyers, and had randomly chosen five personality profiles from that group of 100. Participants read the five profiles, each of which was designed to convey a stereotypical engineer. After each profile, participants were asked to provide the probability that each person was an engineer. In two other conditions the cover story stated there were 70 engineers and 30 lawyers, and an additional, control condition did not provide personality profiles but instead asked for probability estimates immediately after being told about the baserates of lawyers and engineers. In this more direct test of representativeness Kahneman and Tversky (1973) found that participants only integrated the base-rate adequately when they were not given personality profiles of the individuals whose occupations were being predicted. This integral study showed that, even when given base-rate information with representative information, people underweighted the base-rate and focused heavily on representative information (personality profiles).

Representativeness as applied to advertising should cause people to overweigh customer reviews (and underweight the base-rate) as a function of the degree to which the customer reviews address critical aspects of the product. In other words, when given evidence (customer reviews) people will use that evidence to order the likelihood of different outcomes (whether the 
product is good or bad) based on how representative those outcomes are to the evidence. Baserate information is almost always in the form of quantities or probabilities, and thus people tend to not map outcomes of quality onto levels of base-rate. In sum, a customer's hypotheses that a product is good or bad are more representative of customer reviews which often use colorful language to describe products and their features.

The observation that case history information is weighed more heavily than base-rate information appears ubiquitous (Bar-Hillel, 1980; Lyon \& Slovic, 1976) and has been shown across many contexts over the past few decades. For instance, outside of the consumer realm Cannon and Quinsey (1995) demonstrated that, when asked to estimate the likelihood of an inmate committing a violent crime upon release, participants relied more heavily on fictional background histories of the inmates than the actual provided statistical information about the percentage of inmates who commit another violent crime upon release (i.e., the base-rate). In addition, a series of studies by Garb (1996) showed similar results in the context of behavioral outcomes in clinical judgments. Thus, despite other avenues of research investigating the finer details of when people neglect base rate information (e.g., Ginosar \& Trope, 1980; Yan \& Sengupta, 2013), there is concise evidence that generally people adhere to case history information at the expense of relevant base-rate data.

In many studies comparing the effect of base-rate to case history information, these two types of information (customer reviews and base-rate data) are used as conditions within a single factor (say information type) in addition to a possible control or no information condition. The problem is that the two types of information are not typically treated independently, thus restricting the scope when making comparisons between the two. First, comparing the two types of information within a factor allows only for unidirectional differences since a particular 
message is either positive or negative. Second, the use of a third control (i.e. no information) condition assesses the absence of both types of information rather than the absence of either type of information independently. An additional benefit of manipulating base-rate and case history information independently is an examination of the effect of using both types of information together rather than each type in isolation. As stated by Allen and Preiss (1997), "The unanswered issue is whether a combination of proof would be more effective than a single proof' (pg. 129). An important question for marketers is whether or not individuals rely or weigh case history information more than base-rate information when evaluating products online. To best answer this question, a study exploring base-rate versus case history effects by manipulating each type of information independently from one another seems warranted.

This study manipulated the valence of both base-rate and case history information when participants read a hypothetical description of a health beverage. In addition, each manipulation of valence has a control condition where either base-rate or case history information about the product is absent. Given that the majority of past research supports a bias toward case history information using the theoretical rationale of the representativeness heuristic (Kahneman \& Tversky, 1972; 1973), this study predicts that evaluations of the product will be based on case history information more than base-rate information. Specifically:

H1: Participants' attitudes about the product will be significantly affected by the valence of the base-rate information presented independent of the valence of case history information presented.

H2: Participants' attitudes about the product will be significantly affected by the valence of the case history information presented independent of the valence of base-rate information presented. 
H3: Participants' attitudes about the product will be significantly affected by the interaction between base-rate valence and case history valence. In the absence of case history information, base-rate valence will significantly affect product attitudes, however, base-rate valence will not significant affect attitudes in the presence of case history information.

\section{Method}

\subsection{Participants}

Two hundred ninety-one introductory psychology students from a large Midwestern university participated in an online study to fulfill a course requirement. One hundred eighty-five students were female $(63.6 \%)$ and $232(79.7 \%)$ students identified themselves as Caucasian. The average student age was 18.8 years.

\subsection{Design and Materials}

This study used a between-participant experimental design. The first independent variable was the valence of base-rate information presented to participants, consisting of positive, negative, neutral, and no base-rate information. All base-rate information was presented in a tabular fashion similar to those used on actual consumer websites. The lowest possible rating for the product was one star and the highest was five stars. Participants in the no base-rate condition were not shown any customer ratings for the product. Participants in the other conditions were shown a table displaying the number of customers who gave the product a particular number of stars (i.e. 1 star, 2 stars, etc.). For participants in the negative base-rate condition, the table was heavily skewed with the large majority of customers giving the product either one or two stars. Specifically, the table showed that 182 customers provided one star, 107 provided two stars, 23 provided three stars, 17 provided four stars, and 10 provided five stars. 
Participants in the neutral condition were shown a table where 9 customers provided one star, 84 provided two stars, 182 provided three stars, 87 provided four stars, and 6 provided five stars. Participants in the positive base-rate condition were shown a table where 10 customers provided one star, 17 provided two stars, 23 provided three stars, 107 provided four stars, and 182 provided five stars. Table 1 lists the distribution of consumer ratings for the negative, neutral, and positive conditions.

Table 1

Base rate stimuli: Distribution of consumer ratings

\begin{tabular}{lccc}
\hline Base rate & Negative & Neutral & Positive \\
\hline 5 stars & 10 & 6 & 182 \\
4 stars & 17 & 87 & 107 \\
3 stars & 23 & 182 & 23 \\
2 stars & 107 & 84 & 17 \\
1 star & 182 & 9 & 10 \\
\hline
\end{tabular}

The second independent variable was the valence of case history information, consisting of positive, negative, and no case history information. Three electronic word of mouth messages were used to present case histories. Each message was between three and five sentences in length. To best reflect the types of case histories written on actual websites, the messages used in this study were fairly vivid in nature. An excerpt from a positive message is: "When I first tried it, I thought wow this is pretty much the best thing I've ever tasted." An excerpt from a negative message is: "This is just truly the worst beverage I have ever tried in my life." Participants were told that the set of customer reviews was randomly selected from the total number of reviews. Participants were not told the customer rating associated with each review. So if a customer review was negative in valence, participants were not told whether the customer gave a one or two star rating. Since 27 customers provided a one or two star rating within the positive base rate 
condition, it is possible that three negative reviews were selected from pool of reviews. Even though the chance of selecting three negative reviews in the positive base rate condition is small, this method seemed the most appropriate when comparing the influences of the ratings and reviews because the authors needed to provide a sufficient number of reviews to influence participants without the use of mixed messages. Since one or two outlying messages could be easily discounted, the authors tested a set of three messages.

A pilot test consisting of 88 students from the same participant pool was conducted to assess the valence and strength of the positive and negative case history messages. Eight participants had missing values for the pretest, so the pretest data consisted of 80 participants. The pretest used a within-subject design where participants rated the positive and negative sets of case history messages. Order of the message presentation was randomized between the participants (i.e. Positive-Negative or Negative-Positive). The valence of the messages was measured using a single 7-point Likert item asking participants how positive or negative each set of comments were. The anchors for this item were "extremely negative" and "extremely positive" where higher values represented more positive valenced comments. A factorial ANOVA showed a significant interaction between order and message valence on this item, $F(1$, 78) $=3899.14, p<.001, \eta_{p}^{2}=.980$. When exposed to positive messages followed by negative messages, participants rated the first message $(M=6.78, S D=0.67)$ significantly higher in positive valence than the second message $(M=1.00, S D=0.00), F(1,36)=27.38 .63, p<.01, \eta^{2} p$ $=.987$. When exposed to negative messages followed by positive messages, participants rated the first message $(M=1.18, S D=0.76)$ significantly lower in positive valence than the second message $(M=6.72, S D=0.45), F(1,42)=1594.54, p<.001, \eta^{2}{ }_{p}=.974$. Overall, these simple effect analyses showed that participants rated the positive messages significantly higher in 
positive valence across both orders $(M=6.75, S D=0.56)$ than the negative messages across both orders $(M=1.10, S D=0.56)$.

The strength of the messages was measured using another 7-point Likert item asking participants how much weight (i.e. consideration) they would give to the comments if they were going to purchase the product. The item's anchors were "no weight" and "a lot of weight" with higher values representing more strength. A factorial ANOVA showed no significant interaction between order and message strength, $F(1,78)=0.76, p=.387, \eta_{p}^{2}=.010$. The results of this analysis showed that participants had equivalent ratings of strength for the positive $(M=5.41$, $S D=1.31)$ and negative $(M=5.59, S D=1.56)$ sets of comments regardless of the order in which they were presented. These results demonstrate that the manipulation of case history valence was successful since the comments showed different valences with equivalent strengths. Participants in the no case history condition were not exposed to any case history messages, but were still exposed to one of the four base-rate conditions.

Both base-rate information and case history information were presented to participants simultaneously using a single page to prevent possible order effects. Listed above the base-rate and case history information was a simple description of the product itself which described its ingredients (e.g. vitamin C); this allowed for product evaluation for participants in the no baserate, no case history condition. The dependent variable was evaluation of the product, measured using a Likert item asking participants to report the degree to which they would like or dislike the product ( $1=$ strongly dislike, $9=$ strongly like).

\subsection{Procedure}

After consenting to participate, participants were asked to read a hypothetical webpage concerning a novel health beverage. Participants read all of the information and then rated the 
product. After viewing the possible base-rate and/or reading case history information, participants rated the product and completed open-ended demographic questions. After completion of the study, participants were thanked for their participation and debriefed.

\section{Results}

This study used a 4 X 3 factorial ANOVA to assess the effects of base-rate and case history information on participants' evaluation of the product. Preliminary checks using Tabachnick and Fidell's (2007) standards did not reveal violations of statistical assumptions. Two one-way ANOVAs were performed before conducting the main analysis to assess the valence and strength of the case history comments for the present sample. The valence and strength of the comments were measured using the same items described in the method section except the items for this sample were 9-point items instead of 7-point. The first ANOVA showed a significant difference in valence between positive and negative comments, $F(1,194)=678.44$, $p<.001$, where positive comments $(M=7.84, S D=1.69)$ were rated as significantly more positive than negative comments $(M=1.80, S D=1.55)$. The second ANOVA showed no significant difference in strength between the positive $(M=5.99, S D=1.76)$ and negative $(M=$ $6.11, S D=2.47)$ comments, $F(1,194)=0.16, p=.69$. Thus findings from the preliminary analyses demonstrated that the case history comments had differential valences with equivalent strength; therefore the main factorial ANOVA was performed to assess product attitudes.

The results of the factorial ANOVA showed a significant main effect of base-rate valence on product evaluation, $F(3,277)=8.48, p<.001, \eta^{2}=.084$. Tukey comparisons showed that product evaluation was significantly higher for positive, neutral, or no base-rate information compared to negative base-rate information. No significant differences between the positive, neutral, and no base-rate conditions were found. The results also showed a significant main 
effect of case history valence on product evaluation, $F(2,277)=197.48, p<.001, \eta^{2}{ }_{p}=.588($ see Figure 1).

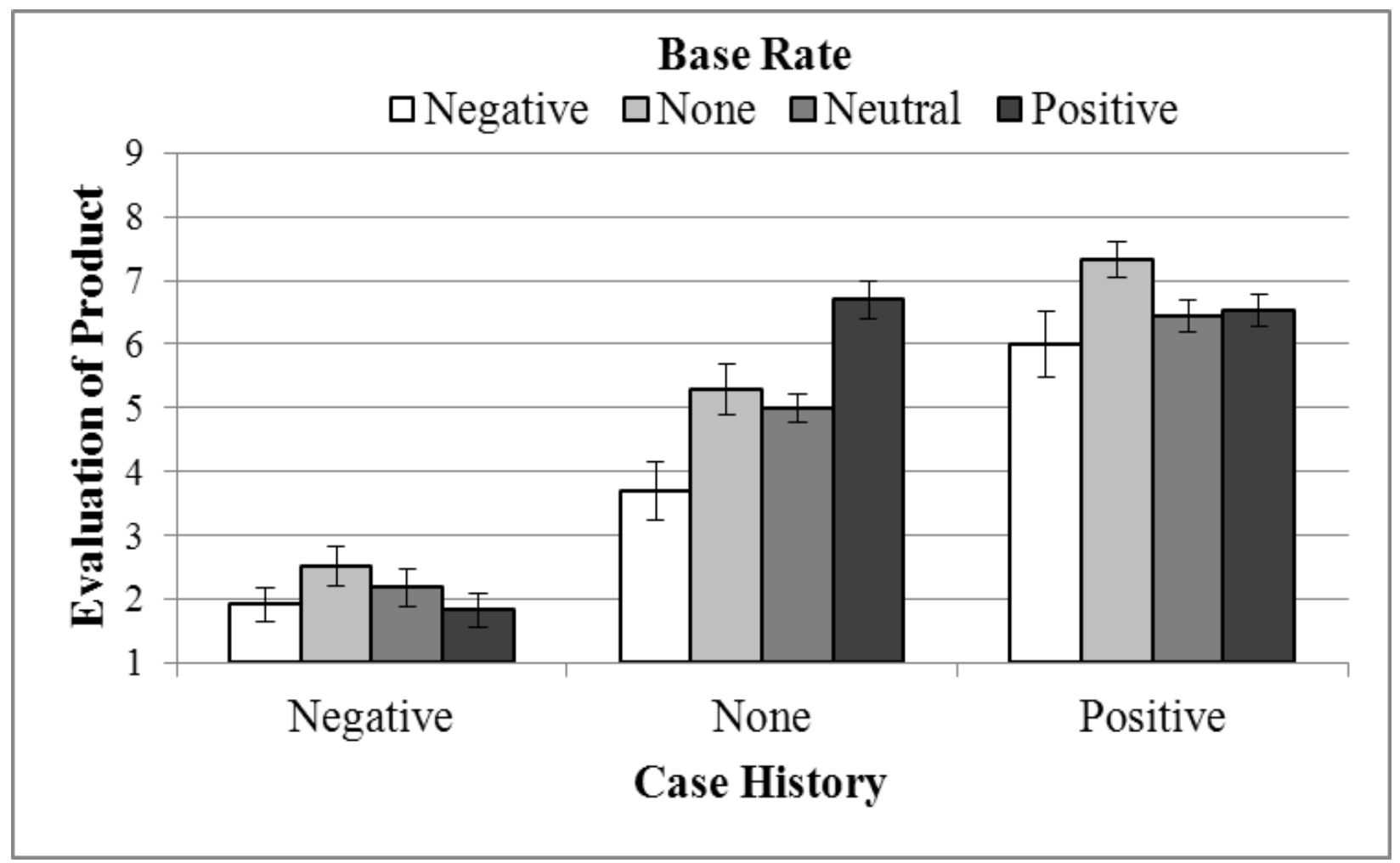

Tukey comparisons showed that product evaluation was significantly higher in the positive case history condition than the no case history and negative case history conditions (see Table 2). Product evaluation was also significantly higher in the no case history condition than the negative case history condition. The main effects were qualified, however, by a significant twoway interaction of base-rate valence and case history valence on product evaluation, $F(6,277)=$ 4.61, $p<.001, \eta^{2}=.091$. To explore this interaction, simple effect analyses were conducted for each separate case history condition.

When no case history information was present, product evaluation was significantly affected by base-rate valence, $F(3,90)=11.87, p<.001, \eta^{2}{ }_{p}=.283$. Tukey comparisons showed 
that product evaluation was significantly higher in the positive base-rate condition than the no, neutral, and negative base-rate conditions (see Table 2).

Table 2

Differences in product evaluation per experimental condition

\begin{tabular}{lccccc}
\hline \multicolumn{5}{c}{ Base Rate } \\
\hline Case history & Negative & None & Neutral & Positive & Collapsed \\
\hline Negative & $1.92^{\mathrm{a}}$ & $2.52^{\mathrm{a}}$ & $2.18^{\mathrm{a}}$ & $1.83^{\mathrm{a}}$ & $2.12^{\mathrm{1}}$ \\
& $(1.35)$ & $(1.67)$ & $(1.40)$ & $(1.27)$ & $(1.45)$ \\
None & & & & \\
& $3.70^{\mathrm{a}}$ & $5.30^{\mathrm{b}}$ & $5.00^{\mathrm{b}}$ & $6.70^{\mathrm{c}}$ & $5.17^{2}$ \\
& $(2.20)$ & $(1.92)$ & $(1.16)$ & $(1.43)$ & $(1.99)$ \\
Positive & & & & & \\
& $6.00^{\mathrm{a}}$ & $7.33^{\mathrm{b}}$ & $6.44^{\mathrm{ab}}$ & $6.54^{\mathrm{ab}}$ & $6.61^{3}$ \\
& $(2.45)$ & $(1.41)$ & $(1.26)$ & $(1.22)$ & $(1.68)$ \\
Collapsed & $3.79^{\mathrm{a}}$ & $5.04^{\mathrm{b}}$ & $4.64^{\mathrm{b}}$ & $5.04^{\mathrm{b}}$ & 4.64 \\
& $(2.62)$ & $(2.62)$ & $(2.15)$ & $(2.61)$ & $(2.55)$ \\
\hline
\end{tabular}

${ }^{\mathrm{a}}$ Means with different letter subscripts across columns are significantly different.

${ }^{\mathrm{b}}$ Means with different number subscripts across rows are significantly different.

${ }^{\mathrm{c}}$ Values in parentheses represent standard deviations.

Product evaluation was also significantly higher in the neutral and no base-rate conditions compared to the negative base-rate condition. No significant difference was found between the neutral and no base-rate conditions.

For positive case history information, product evaluation was significantly affected by the base-rate valence, $F(3,94)=2.90, p=.039, \eta^{2} p=.085$. Despite the significant simple effect, product evaluation was only significantly higher in the no base-rate condition than the negative base-rate condition. No other significant differences were found between the positive, neutral, negative, and no base-rate conditions. Finally when negative case history was present, product evaluation was not significantly affected by base-rate valence, $F(3,93)=1.18, p=.321, \eta_{p}^{2}=$ 
.037. Product evaluation was similar for the positive, neutral, negative, and no base-rate conditions.

\section{Discussion}

Generally speaking, this study demonstrated that individuals place more emphasis or weight on case history information at the expense of base-rate information when evaluating an item. All three hypotheses were supported in this study. When examined independently of one another, both base-rate valence and case history valence affected participants' attitude about the product. However, when both base-rate and case history information were examined together, product attitudes were affected by the case history information and not the base-rate information.

The emphasis placed on case history information coincides with the findings typically found in judgment and decision making studies rather than research using more marketing oriented contexts. Specifically, the findings seem to compare to Ginosar and Trope (1980) and Kahneman and Tversky (1973) by showing that base-rate information is not ignored completely but is used specifically when case history information is absent. When representative case history information is present, however, this study shows support for base-rate neglect (Kahneman \& Tversky, 1972). From a theoretical standpoint, several questions remain regarding the bias toward case history information. One interesting question is whether or not this bias diminishes or disappears when case history information is not representative. By case history representativeness, we mean the degree to which a qualitative statement(s) describes the typical or essential properties of a target object. This definition is adapted from the definition of the representativeness heuristic used by Medin, Ross, and Markman (2005). In this sense, is nonrepresentative case history information ignored and given zero weight, given very little weight, or do attitudes boomerang (Petty \& Cacioppo, 1986) in the presence of such information? 
Another important theoretical issue is how to present base-rate information in ways to increase its weight when representative case history information is presented. One possible method could be changing the display of base-rate information. Rather than using a tabular listing of consumer ratings, other pictorial representations of base-rate information such as venn diagrams, dotted venn diagrams, or icon displays (Brase, 2009) may compel individuals to weigh such information more. From a JDM perspective, the use of dotted venn diagrams or icon displays should increase the weight of base-rate information since these displays show individualized information rather than percentile information (Brase, 2009).

For online marketers, several questions also remain concerning the generalizability of these results. One factor which might influence base-rate neglect in an online shopping context is the psychological distance between the shopper and the product (Yan \& Sengupta, 2013). Yan and Sengupta show that case history information impacts judgment when psychological distance is low while base rate impacts judgment when distance is high. In online shopping contexts, psychological distance could pertain to whom the gift is being bought for. Psychological distance would be low when the product is being purchased for the self and high when the product is being purchased as a gift for someone else. In this study, the judgment concerns the self, which aligns with Yan and Sengupta's findings. An interesting extension of this work along with Yan and Sengupta would manipulate the psychological distance to assess if base rate neglect decreases when the product is being purchased for another person. Besides the psychological distance between the shopper and product, the type of case history narrative may impact individuals' attitudes. As done in this study, Shaffer and Zikmund-Fisher (2013) note that different narrative types are typically merged together when creating case history information in research. For Shaffer and Zikmund-Fisher, combining these narratives together when creating 
case history information is problematic since they hypothesize (but do not empirically show) that different narrative types have differential effects on individual judgment/decision making. Thus one important extension of this work would manipulate different narrative types when presenting case history information to assess which type (if any) is more persuasive than another. Lastly, the method used to select case history information may affect individuals' judgment of the product. Unlike a random selection method, case history information may be discounted more readily when they are presented based on when they are posted or in terms of importance.

The implications of this study suggest that most webpage space should be devoted to presenting detailed consumer reviews about a product compared to consumer ratings. The emphasis on case history information, however, can present a problem in online shopping contexts when such information biases individuals' evaluations of a product. For many online webpages, base-rate information provides a more holistic summary of a product's quality. Thus the reliance on case history information may lead individuals to like or dislike a product based on a few pieces of data while ignoring a larger amount of data. For this reason, finding methods of making base-rate information more salient during evaluation or decision making is important for the online marketing community. Again, one possible method could be changing the display of base-rate information. If more individualized displays increase the weight placed on base-rate information, such changes would greatly improve online consumer websites by helping consumers use a more balanced approach when evaluating products. Although it is the focus of this study, the online consumer context is not the only online context where base-rate neglect may have an impact. For many educators worldwide, this issue also applies for evaluations of instructors using websites such as ratemyteachers.com and ratemyprofessors.com. In these contexts, it is possible that students and parents evaluate educators based on the information 
contained in a few case history comments rather than the information presented in base-rate form. When this happens, students may decide not to take a class taught by a particular instructor or allow a child to be taught by an individual. Thus finding ways to present both forms of information so that both are given weight and lead to more balanced evaluative approach should be an emphasis for researchers. 


\section{References}

Allen, M., \& Preiss, R. W. (1997). Comparing the persuasiveness of narrative and statistical evidence using meta-analysis. Communication Research Reports, 14(2), 125-131.

Baesler, E. J., \& Burgoon, J. K. (1994). The temporal effects of story and statistical evidence on belief change. Communication Research, 21(5), 582-602.

Bar-Hillel, M. (1980). The base-rate fallacy in probability judgments. Acta Psychologica, 44(3), 211-233.

Borgida, E., \& Nisbett, R. E. (1977). The differential impact of abstract vs. concrete information on decisions. Journal of Applied Social Psychology, 7(3), 258-271.

Brase, G. L. (2009). Pictorial representations in statistical reasoning. Applied Cognitive Psychology, 23(3), 369-381.

Cannon, C. K., \& Quinsey, V. L. (1995). The likelihood of violent behavior: Predictions, postdictions, and hindsight bias. Canadian Journal of Behavioual Science, 27(1), 92-106.

Dickson, P. R. (1982). The impact of enriching case and statistical information on consumer judgments. Journal of Consumer Research, 8(4), 398-406.

Garb, H. N. (1996). The representativeness and past-behavior heuristics in clinical judgment. Professional Psychology: Research and Practice, 27(3), 272-277.

Ginosar, Z., \& Trope, Y. (1980). The effects of base-rates and individuating information on judgments about another person. Journal of Experimental Social Psychology, 16(3), 228242.

Hamill, R., Wilson, T. D., \& Nisbett, R. E. (1980). Insensitivity to sample bias: Generalizing from atypical cases. Journal of Personality and Social Psychology, 39(4), 578-589.

Kahneman, D., \& Tversky, A. (1972). Subjective probability: A judgment of representativeness. 
Cognitive Psychology, 3(3), 430-454.

Kahneman, D., \& Tversky, A. (1973). On the psychology of prediction. Psychological Review, 80(4), 237-251.

Kazoleas, D. C. (1993). A comparison of the persuasive effectiveness of qualitative versus quantitative evidence: A test of explanatory hypotheses. Communication Quarterly, 41(1), 40-50.

Koballa, T. R. (1986). Persuading teachers to reexamine the innovative elementary science programs of yesterday: The effect of anecdotal versus data-summary communications. Journal of Research in Science Teaching, 23(5), 437-449.

Krupat, E., Smith, R. H., Leach, C. W., \& Jackson, M. A. (1997). Generalizing from atypical cases: How general a tendency? Basic and Applied Social Psychology, 19(3), 345-361.

Ledgerwood, A., Wakslak, C. J., \& Wang, M. A. (2010). Differential information use for near and distant decisions. Journal of Experimental Social Psychology, 46(4), 638-642.

Lyon, D., \& Slovic, P. (1976). Dominance of accuracy information and neglect of base rates in probability estimation. Acta Psychologica, 40(4), 287-298.

Medin, D. L., Ross, B. H., \& Markman, A. B. (2005). Cognitive psychology (4th ed.). Hoboken, NJ: Wiley.

Nisbett, R. E., \& Borgida, E. (1975). Attribution and the psychology of prediction. Journal of Personality and Social Psychology, 32(5), 932-943.

Petty, R. E., \& Cacioppo, J. T. (1986). The elaboration likelihood model of persuasion. In: L. Berkowitz (Ed.), Advances in experimental social psychology. New York: Academic Press.

Shaffer, V. A., \& Zikmund-Fisher, B. J. (2013). All stories are not alike: A purpose-, content-, 
and valence-based taxonomy of patient narratives in decision aids. Medical Decision Making, 33(1), 4-13.

Slater, M. D., \& Rouner, D. (1996). Value-affirmative and value-protective processing of alcohol education messages that include statistical evidence or anecdotes. Communication Research, 23(2), 210-235.

Tabachnick, B. G., \& Fidell, L. S. (2007). Using multivariate statistics (5th ed.). Boston: Pearson.

Yan, D., \& Sengupta, J. (2013). The influence of base rate and case information on health-risk perceptions: A unified model of self-positivity and self-negativity. Journal of Consumer Research, 39(1). 